\title{
Effect of Cassava Processing to the Environment in South East, Nigeria - Implication on Adoption of Cassava Processing Technology
}

\author{
Ume, S.I. ${ }^{1}$, Onwujiariri, U.J. ${ }^{2}$ and Nwaneri, TC ${ }^{1}$ \\ ${ }^{1}$ Department of Agricultural Extension and Management. Federal College of Agriculture Ishiagu, \\ Ivo Local Government Area of Ebonyi State, Nigeria. \\ ${ }^{2}$ Department of Home and Rural Economics. Federal College of Agriculture Ishiagu, Ivo Local \\ Government Area of Ebonyi State, Nigeria.
}

Corresponding Author: umesmilesi@gmail.com

Keywords: Effect, Cassava processing, Environment, South east, Implication, Adoption, Technology

\begin{abstract}
Effect of adoption of improved cassava processing technology to the environment in South East, Nigeria. The specific objectives of the study are to describe the socio economic characteristics of the processors; identify the effect of cassava processing to the environmental; identify different forms of cassava processing; identify the technologies used by the processors to abate pollution; determine the factors affecting the decision of the processor in adopting of the technologies and identify the constraints to cassava processing in the study area. One hundred and twenty processors were selected from the States. A well structured questionnaire was used to collect information needed for the study. The objectives were addressed using percentages, logistic model analysis and factor analysis. The results show that most cassava processors were aged, fairly educated, well experienced and membership of organization. The different forms of cassava processing in the study area are gari, fufu, tapioca, starch and flour. The effects of cassava processing on the environment were odour, flies, mosquito dust, cyanide, carbon compound and waste water. The technologies adopted by the processor in order to abate pollution were use of collection pit, heap and burn, use of protective devices, source of fuel and dumping in the farm. The determinant factors to adoption of the technologies to abate pollution were education of the processors, credit, and membership of organization, processing experience and extension services. The constraints to cassava root processing were poor access to credit, high price of processing equipment, Poor pricing of products, poor infrastructure, poor pricing of products, irregular suppiy of tubers and Poor market information. There is need to ensure processors' access to educational programs such as adult program, extension services, credit facilities and regular supply of cassava roots.
\end{abstract}

\section{Introduction}

Cassava was a famine reserve crop as it is source of ease and reliable source of food during drought and hunger periods, but today a staple food and cash crop for global industrial uses [1, 2]. Cassava (Manihot esculenta Crantz), apart from being the fifth most important food crop in the world, but has effectively integrated into many farming and food systems in the continents where it is cultivated [2].Africa produces over 54\% of the world's cassava with Nigeria having the highest global production of about 54.8 million metric tonnes in 2014 [3]. Cassava is grown in all agroecological zones of Nigeria but production is highest in the North-Central, South East and South South regions $[4,5]$. The cassava crop inclination to smallholder farmers in the continent could be attributed to its possession of high productivity under adverse conditions, all-year-round availability as well as its wide adaptability to various farming and food systems $[1,8]$. Furthermore, it is an important industrial raw material and source of income for marketers, processors and labourers $[6,7]$. Traditionally, cassava roots are process by a array of techniques in many singular products and used in different ways according to local customs and preference to provide the carbohydrate part of the diet $[9,10]$. Processing of cassava helps in reducing food loses and stabilizes seasonal 
fluctuation in supply of the crop. Also, it helps to increase the shelf life of the products, facilitate transportation and marketing, reduce cyanide content and improve palatability of the products [11, $12]$.

Cassava can be processed into varied forms; gari, fufu,flour, starch, abacha, and Lafun which commands market both locally and internationally [9, 11]. In Nigeria, cassava processing could done through small family-size units to modern large-scale factories $[10,11]$. The small scale cassava processing unit is often very tedious and labour intensive [10]. The improved processing technology is of different models and variations of mechanical cassava graters, industrial gari fryers, mechanized milling cassava chips, water expressing and milling, and stationary or pushcartmounted graters powered by petrol or diesel engines. This modern method is designed to remove the constraints that processors face at the household level processing method with intension of optimizing their outputs [11]. Indeed, the beneficial of the technology; including improved product quality, reduced bulk, and extended shelf life and made it possible for quality cassava products to be transported at reduced costs to urban areas markets where demand is more[9].

However, the growing use of these technologies and the clusters of the numerous of small scale cassava processing units in the study area is causing environment and human health concern, particularly in the rural areas of the developing countries $[2,12]$. For instance, the water discharged (affluent) from a cassava processing factory is acidic with a high organic matter content (soluble carbohydrates and proteins) and suspended solids (lipids and non-soluble carbohydrates - starch or cellulose fibers) is capable of emanating foul odour and unappealing sight and breeding ground for mosquitoes and houseflies especially if the wastes are untreated before discharging them into stagnant ditches and gutters $[13,14]$. Furthermore, other forms of processing that does not require water, for instance cassava chips production is capable of generating dust waste, which according to literature could result to heart disease, lung cancer and asthma to the victims [14]. In addition, the organic matter generating from retting of cassava is a problem, causing high BOD (biological oxygen demand) and COD (chemical oxygen demand) and eutrophication of waterways, leading to increase in the number of microorganisms and the growth of algae. This can alter water quality and/or change the aquatic ecology, affecting plants and animals, human health and visual aspects [15]. As well, noise generated by the petrol or diesel engines used in cassava milling operations can contribute to noise - induced hearing loss and cardiovascular effects in human beings [17]. Besides, waste water also contains cyanide as well as sulphur dioxide which result in dissipation, if channeled into water ways un treated[16] and to pollute water bodies like rivers, streams and aquifer leading to death of aquatic animals and contamination of open wells and bore holes [14].

Cassava processing related pollution control is complicated especially in most rural areas of Sub Saharan Africa, and reasons often deduced among literatures, including; most processors are in the region are resource poor (financial and technical resources) to manage wastes and lax in government agencies to enforce environmental pollution laws because of among others corruption and logistic problem $[1,10,11]$. Furthermore, the incapacitation of the countries in that region to develop low-cost treatment processes for small- and medium-scale cassava processors taking cognizance of our low technological endeavor [20, 21]. In many developed and few in developing countries, enormous innovations are bound in curtailing maximally environmental pollution emanating from agricultural wastes; including land filling, fermentation of cassava peels, ensiling of solid residue, animal feed or dried, used as fuel and soil conditioner, use of pit, lagoon, digester and biological method [19,22]. However, the experience with adoption of these innovation has proved less effective elsewhere, especially in Africa. For instance, the extent of its impact on environmental pollution in most rural area of the country is not known. The position of cassava processors in the adoption of the technologies need to be investigated, as such knowledge is lacking especially in the study area.

The specific objectives of the study are to:

i. describe the socio economic characteristics of the processors;

ii. identify different forms of cassava processing

iii. identify the effect of cassava processing to the environmental; 
iv. identify the technologies used by the processors to abate pollution

v. determine the factors affecting the decision of the processor in adopting environmental free technologies and

vi. Identify the constraints to cassava processing in the study area.

\section{Materials and Methods}

The South East Nigeria was the study area. The zone lies between latitude $5^{0} 9^{\prime}$ and $7^{0} 75^{\prime} \mathrm{N}$ of Equator and longitude $6^{0} 85^{\prime}$ and $8^{0} 46^{\prime}$ East of Greenwich Meridian. It has a total land mass of 10,952.400ha. The zone has population of $16,381.729$ people [24]. The zone is made up of five states viz: Abia, Anambra, Ebonyi, Enugu and Imo States. It is bordered in the North by Benue and Kogi States, in the West by Delta and Rivers States, in the South by Akwa Ibom State and in the East by Cross River State. South east states has two major seasons in the year, the rainy season which lasts from the month of April - October and the dry season that lasts from November to March. The temperature of the area varies between $18^{\circ} \mathrm{C}-34^{\circ} \mathrm{C}$. The people are agrarians and involved in non-agricultural activities, including civil service, petty trading, vulcanizing, driving, carpentry and auto mechanics.

A multi-stage random sampling technique was used to select states, Local Government Area (LGA), towns and processors. In the first stage 1, three states were randomly selected from five states. In the second stage, five LGAs were randomly selected from each State. These brought to a total of fifteen LGAs. In the third stage, four towns were selected from each LGA, making a total of sixty towns. Finally, from the lists of processors obtained from Women in Agriculture (WIA) arm of Agricultural Development Program (ADP), a total of one hundred and twenty processors (30 gari, 30 fufu, 30 tapioca and 30 four) for detailed study were selected. A structured questionnaire was used to elicit information on primary data. The objectives I, ii, iii, and vi was analyzed using percentage responses. Objective iv was analyzed using logistic regression model.

\section{Model Specification Logistic regression model}

The Logistic regression model gives the effect of cassava processing to the environment in South East, Nigeria as well as the predicted probabilities of adoption (likelihood of adoption). The dependent variable in the empirical model is the possibilities or not processors using improved processing technologies. Logistic regression characterizing cassava processing technology adoption by the sampled processors could be expressed as follows;

$$
\mathrm{E}(\mathrm{Yi})=\mathrm{P}(\mathrm{Yi})=\mathrm{e} \alpha+\beta \mathrm{Zi} / 1+\mathrm{e} \alpha+\beta \mathrm{Zi}
$$

$\mathrm{Pi}$ is the probability of the ith processor with ith attributes likely to use the technologies $\mathrm{E}(\mathrm{Yi})+\mathrm{P}(\mathrm{Yi})=1$, where $\mathrm{Yi}=1$ if the individual processors use the technologies and $\mathrm{Yi}=0$ if the Individual processors that do not use the technology.;

$\mathrm{Zi}$ represents a vector of attributes associated with the ith individual. $\beta \mathrm{i}$ is the vector of the estimated coefficients. The regression model is linearlized as follows; In (pi/ (1- pi)

$$
=\beta o+\beta_{1} Z_{1}+\beta_{2} Z_{2} \ldots \beta_{8} Z_{8}+\varepsilon
$$

The dependent variable is the natural log of the probability of adopting $(\mathrm{P})$ divided by the probability of not adopting it (1-P). $\beta$ o is the intercept term, and $\beta_{1}, \beta_{2} \ldots \beta_{8}$ are the coefficients associated with each explanatory variable, $Z_{1}, Z_{2} \ldots Z_{8}$.

Explicitly logistic regression model can be represented as

$$
\mathrm{Y}=\mathrm{b}_{0}+\mathrm{b}_{1} \mathrm{~m}_{1}+\mathrm{b}_{2} \mathrm{~m}_{2}+\mathrm{b}_{3} \mathrm{~m}_{3}+\mathrm{b}_{4} \mathrm{~m}_{4}+\mathrm{b}_{5} \mathrm{~m}_{5}+\mathrm{b}_{6} \mathrm{~m}_{6}+\mathrm{b}_{7} \mathrm{~m}_{7}+\mathrm{b}_{8} \mathrm{~m}_{8}+\mathrm{e}
$$

Where $\mathrm{Yi}=$ rate of adoption of cocoyam technology use $\left(\right.$ percentage) $\mathrm{m}_{1}=$ Gender (Dummy) $\mathrm{m}_{2}=$ Age of processors (Years) $m_{3}=$ Education level (Years) 
$\mathrm{m}_{4}=$ Number of visits by extension agents in the year. $\mathrm{m}_{5}=$ Access to credit (Naira)

$\mathrm{m}_{6}=$ Processing experience (Years) e $=$ Error term

The specific objectives of the study are to:

i. describe the socio economic characteristics of the processors;

ii. identify different forms of cassava processing

iii. identify the effect of cassava processing to the environmental;

iv. identify the technologies used by the processors to abate pollution

v. determine the factors affecting the decision of the processor in adopting environmental free technologies and

vi. Identify the constraints to cassava processing in the study area.

\section{Results and Discussion}

Table I shows that most of the processors were females for gari $(73.4 \%)$, fufu( $83.4 \%)$ and flour (76.7\%) and tapioca(93.4\%). Processing in agriculture generally according to studies $[2,4,7]$ is an idoor activities and often female sterotyped, while males are involved in farming. This finding did not concur with [1,4], who posited that males can afford the financial and labor- intensiveness of the business [3; 7]. Furthermore, most of the respondents in different cassava processing forms as shown in Table 1 were less than 40 years of age, while only $33.4 \%, 23 \%, 20 \%$ and $33.4 \%$ of gari, fufu, tapioca and flour respectively were above 40 years. Youthful people can overcome rigors in cassava processing and could be receptive to adoption of innovations that could be better their welfare and the environment in which they operate upon [2]. Besides, most of the respondents (73.3\%, 70\%, 60\% and 53.4\% of gari, fufu, tapioca and flour respectively.) were married. Married individuals in ideally situation are assume to have children and household members who could help in accomplishing environmental free processing technology activities, thus helping in reducing cost of processing as well curtailing pollution rate maximally [2].

Most of the respondents $(53.4 \%, 63.4 \%$ and $70 \%$ of gari, tapioca and flour processors respectively) had no access to credit, while only $53.4 \%$ of the fufu processors had access. The poor access of the processors to credit could be ascribed to high interest rates charged by bankers and short period of loan repayment [29]. Credit helps processors in acquiring materials inputs to be used in adoption of free environmental cassava processing in order to curtail maximally environment degradation [1]. As well, only $80 \%$ and $70 \%$ of the gari and flour processors were members of different organizations, while $80 \%$ and $70 \%$ of the fufu and tapioca respectively were not. The non membership of fufu and tapioca processors could be linked to absence of cooperative in the area. The work of [4] is in agreement to the above assertion. They reported that cooperative members could through sharing of ideas could gain more insights in consequences of pollution and the need to abate it in the course of executing their processing business Cooperative enables members in adopting technologies through training in order to abate possible environment pollution emanating from their processing practices[27]. More so,76.4\%, $66.6 \%, 66.3 \%$ and $66.6 \%$ of the sampled gari, fufu, tapioca and flour respondents respectively had western education. Educated people can easily grasp on the need to conserve the environs through yielding to adoption of environmental friendly innovations [2]. Moreover, $76 \%$ of the respondents had been in in gari processing for the past 10 years, Long years of processing experience enriches the processor with processing knowledge that could help he/she in prevailing over intrinsic environmental problems that are connected with cassava processing. [1] finding concurred with the above finding. In addition, $33.4 \%, 40 \%, 73.4 \%$ and $60 \%$ of the sample gari, fufu, tapioca and flour processors respectively had poor extension outreach, Extension services facilitates in disseminating environmental free processing innovations to the processors for a healthy environs[29]. Studies [2, 3, 5] were in harmony with above statement. They opined that extension agents could enlighten the processors with improved environmental technological innovations in cassava processing through giving them technical assistant. 
Table 1. Distribution of Processors according to Socio economics Characteristics

\begin{tabular}{|c|c|c|c|c|c|c|c|c|}
\hline Variable & Gari & & Fufu & & $\begin{array}{c}\text { Tapioc } \\
\text { a2 }\end{array}$ & & Flour & \\
\hline & Frequency & Percentage & Frequency & Percentage & Frequency & Percentage & Frequency & Percentage \\
\hline \multicolumn{9}{|l|}{ Gender } \\
\hline Male & 8 & 26.7 & 5 & 16.7 & 2 & 6.7 & 23 & 23.4 \\
\hline Female & 22 & 73.4 & 25 & 83.4 & 28 & 93.4 & 7 & 76.7 \\
\hline \multicolumn{9}{|l|}{ Age } \\
\hline Below 40 & 20 & 66.7 & 23 & 76.7 & 24 & 80 & 20 & 66.7 \\
\hline Above 40 & 10 & 33.4 & 7 & 23 & 6 & 20 & 10 & 33.4 \\
\hline \multicolumn{9}{|l|}{ Organization } \\
\hline Member & 24 & 80 & 6 & 20 & 9 & 30 & 21 & 70 \\
\hline Non Member & 6 & 20 & 24 & 80 & 21 & 70 & 9 & 30 \\
\hline \multicolumn{9}{|l|}{ Ext. Serv. } \\
\hline Contact & 20 & 66.7 & 18 & 60 & 8 & 26.7 & 12 & 40 \\
\hline Non Contact & 10 & 33.4 & 12 & 40 & 22 & 73.4 & 18 & 60 \\
\hline \multicolumn{9}{|l|}{ Access to Credit } \\
\hline None & 16 & 53.4 & 14 & 46.7 & 19 & 63.4 & 21 & 70 \\
\hline Access & 14 & 46.7 & 16 & 53.4 & 11 & 36.7 & 9 & 30 \\
\hline \multicolumn{9}{|l|}{ Educational level } \\
\hline No formal & 7 & 23.4 & 10 & 33.4 & 11 & 36.7 & 10 & 33.4 \\
\hline Primary & 10 & 33.4 & 8 & 26.7 & 7 & 23.4 & 10 & 33.4 \\
\hline Secondary & 8 & 26.7 & 7 & 23.4 & 8 & 26.7 & 6 & 20 \\
\hline Tertiary & 5 & 16.7 & 5 & 16.7 & 4 & 13.4 & 4 & 13.4 \\
\hline \multicolumn{9}{|c|}{ Year of processing } \\
\hline Below 10 year & 9 & 30 & 10 & 33.4 & 10 & 33.4 & 14 & 46.7 \\
\hline Above 10 years & 21 & 70 & 20 & 66.7 & 20 & 66.7 & 16 & 53.4 \\
\hline \multicolumn{9}{|l|}{ Gender } \\
\hline Married & 22 & 73.3 & 21 & 70 & 18 & 60 & 16 & 53.4 \\
\hline Single & 8 & 26.7 & 9 & 30 & 12 & 40 & 14 & 46.7 \\
\hline
\end{tabular}

Source; Field Survey, 2018

Table 2 shows that $20.8 \%$ of the sample processors engaged in starch processing. According to [4] the time of planting and harvesting, and age of plant from planting to harvesting affect starch content, yield and quality of products . Furthermore, $47.1 \%$ of the respondents were into flour production. HQCF is important raw material for the manufacturing of textile, plywood, paper and packaged foods [2]. The processing of cassava roots into high quality cassava flour (HQCF) has the potentials of enhancing market value of cassava, and improve their income and standard of living [3]. Besides, tapioca processing was engaged by $66.7 \%$ of the sampled processors in the study area. Tapioca is a roasted granular product from cassava starch that is widely acceptable, but is currently only produced on a very small scale [3, 4]. In addition, $76.7 \%$ of the sampled processors were into fufu processing. Flour is fermented wet-paste made from cassava. Fufu is very rich in carbohydrate and has smooth texture and ranked next to gari as an indigenous food of most Nigerians in the South East. Traditionally, fufu has the characteristics of being in wet form , unpleasant odour, highly perishable and with a short shelf life compared with gari and lafun [2]. There is high demand for fufu in Nigeria as it has no ethic, religious and social barrier with annual demand according to[31] of 350,000 tonnes and national supply of 300,000 tonnes. Furthermore, $83.3 \%$ of the respondents were into gari processing. Gari is one of the most important granulated cassava products in the study area and usually fermented to impart a sour taste to which depends on consumer preference and market [3]. It is often toasted to extends the shelf-life for ease of transportation to urban markets. The consumption preference for gari by consumers could be it is ready to eat and storable $[1,16,19$.] Statistics on gari consumption according to $[28,29]$ reported that approximately that 28.41 million people and $31 \%$ of Nigerian community consume gari once, twice and thrice daily respectively. 
Table 2. Identify different forms of cassava processing in the study area

\begin{tabular}{|l|c|c|}
\hline \multicolumn{1}{|c|}{ Variable } & Frequency & Percentage \\
\hline Gari & 100 & 83.3 \\
\hline Fufu & 92 & 76.7 \\
\hline Tapioca & 80 & 66.7 \\
\hline Flour & 50 & 41.7 \\
\hline Starch & 25 & 20.8 \\
\hline
\end{tabular}

*Multiple responses

Source; Field Survey; 2018

Table 3 shows that $85 \%$ of the sample processors reported that cassava processing results in waste water generating which is capable of polluting the environment. Waste water "squeeze water" emanating from cassava processing waste eater contains HCN, BOD, COD and suspended solids, which if allowed to seep into water bodies could be toxic to aquatic life and render such water unpalatable for human consumption [14]. Literature reveals that in Brazil such waste water could be used as insecticide and herbicide respectively[ 12]. Also, 64.2\% of the respondents complained about releasing of sulphur dioxide from cassava fermentation which can result in environmental pollution. Studies [12, 14, 19] show that sulfur dioxide is used a bleaching and anti- microbial agent in cassava starch industry and could affect the ozone layer resulting in releasing excessive heat to the earth. In addition, sulphur dioxide from plant generator exhaust has the potentials of causing damages to crop and material trough the deposition of acidic liquid and solid aerosols on them [18].

As well, $70 \%$ of the respondents reported hydrogen cyanide has capacity of affecting the environments. According to [16] hydrogen cyanide has high propensity of being toxic to man and animal and aquatic life. This cyanide is found in the cassava peels, press water from gari and farinha production and vapour during gari toasting, could be reduced through ensiled, fermentation and well-ventilated processing apartment respectively [30]. Additionally, dust emanating from chipping and drying operations in cassava as reported by $54.2 \%$ of the respondents is capable of affecting human health. Literature show that dust has the probability of causing respiratory diseases, heart disease catarrh and eye problem to man [17]. Furthermore, 37.5\% of the sampled processors reported the problem of oil spillage. Oil spillage from the generator as asserted by [13] could annihilate wild life habitation, destroy fragile water ecosystem and kill aquatic fish, when seep in large quantity into water bodies through waste water, As well, noise emanating from processing generator has the tendency of causing pollution to the environs as posited by the $79.2 \%$ of the total respondents. Noise as observed by [14] can contribute to noise-induced hearing loss, and cardiovascular to man [32]. Besides, $70 \%$ of the sampled processors opined that the problem of degradation of the environment through use of forest reserve product. Wood, as resource from forest reserve product as reported by $[1 ; 32]$ is the major heat energy source in small-scale cassava processing, especially in boiling, drying or toasting in cassava processing. The pursuit of this resource is capable of affecting the environment through severe deforestation and desertification [2]. What's more, $81.7 \%$ of the sampled processors complained about the problem of organic matter. Organic matter from cassava processing is capable of predisposing the water bodies with high BOD and COD, eutrophication and foul odours, if not treated before being discharged [22]. More so, solid wastes inform of peel wastes, fibrous by product and pulp waste could constitute environmental problem especially during heavy rainfall and large scale production was reported by $90 \%$ of the total respondents. These residues could be disposed through sales as animal feed or dried and used as fuel and soil conditioner[4;8].

As well, odor emanating from uncontrolled fermentation of the organic matter in cassava processing waste was reported by $83.4 \%$. This odour is very distasteful and it is prevalent especially during processing season as waste water could settle or accumulates in ditches or gutters outside the processing arena. Here, odour oozes from these sites, thus making the environs very unpleasant for the inhabitants and passersby [28]. Still, $80 \%$ of the respondents complained about problem of carbon compound as result of pollution. Carbon compound in form of carbon dioxide and carbon 
monoxide emanating from use of firewood in frying of gari and hydrocarbon from generator plants used in cassava processing in conjecture with other green gases is capable of causing global warming. This results in heating the earth through increasing its temperature [32]. Also, the ozone pollution by these gases could result in respiratory disease, cardiovascular disease, throat inflammation, chest pain, and congestion[5, 13].

Table 3. Effect of Cassava Processing to the Environment

\begin{tabular}{|l|c|c|}
\hline \multicolumn{1}{|c|}{ Variable } & Frequency & Percentage \\
\hline Odour & 100 & 83.4 \\
\hline Noise & 95 & 79.2 \\
\hline Flies & 72 & 60 \\
\hline Mosquito & 64 & 53.4 \\
\hline Dust & 65 & 54.2 \\
\hline Oil & 45 & 37.5 \\
\hline Solid waste & 108 & 90 \\
\hline Organic matter & 98 & 81.7 \\
\hline Sulphur dioxide & 77 & 64.2 \\
\hline Forest Reserve & 84 & 70 \\
\hline Carbon compound & 96 & 80 \\
\hline Waste water & 102 & 85 \\
\hline Cyanide & 84 & 70 \\
\hline
\end{tabular}

Multiple Responses Source ; Field Survey, 2018

Table 4 shows that $83.3 \%$ of the total respondents put their wastes for animal feed. [33] reported that peels and other solid waste that is generated from the production of farinha, gari, and chikwangue. Farinha factories is often dried and could be used to feed animals directly and in formulation of livestock feed $[33,34,35]$. Furthermore, the peels and other solid waste can be fed to animal after ensiling them in order to reduce the cyanide level to $4.0 \mathrm{pH}$ and increase the lactic acid [35]. As well, cassava peel is of low digestibility and with toxicity from hydrocyanic acid, but when fermented the toxicity is highly reduced and the enzyme-resistant ligno-cellulose material is converted into a more digestible substrate. Hence, the fermented cassava peel can be used in pig and poultry feed formulation [35]. Also, solid wastes from cassava processing could be used in the farm as soil conditioners and in improving soil fertility as opined by $.66 .7 \%$ of the processors. Studies [6, $19,22]$ revealed that these wastes when dumped in the farms without being properly incorporated into the soil could lead to pollution of the environment with odour and flies. Also, use of waste water as fertilizer source should be done with caution as the high HCN content can have a toxic effect on plant growth [11]. Besides, $56.7 \%$ of the sampled processors used waste water from cassava processing for irrigation. This is a common practice in Africa and there is need to be cautious in the practise to avoid possible soil degradation in the long term[16].

Moreover, $65 \%$ of the respondents opined that they used land filling to dispose their solid wastes. Literatures show that such land to be used for such operations should not be very close to water bodies to avoid ultimate pollution [7]. Furthermore, $80 \%$ of the sampled processors used gadgets such as mouth and nose mask while operating their generator plants to avoid pollution. These protective devices are capable of covering the nose, ear, and mouth in attempt to prevent pollutions emanating from dusts, noise and odour. This could impact positively to guide against problems of respiratory disease asthma and other health related challenges [32]. In addition, $62.5 \%$ of the sampled processors revealed that they heap their wastes and burn them. This practice 
according to [24] is common among large cassava processing industries where the solid wastes are usually too large, hence are dried and burnt. Besides, $85 \%$ of the respondents used pit for collection of effluents and liquid wastes emanating from processing plant and hydraulic press. The problem with pit collection is that in many processing units in rural areas, these pits are not pasted with cement, thereby causing liquid effluents to seep into the soil, consequently soil contamination results [15]. As well in some situation, the pit often breaks or filled to brim and start overflowing because of constant accumulations of solid wastes from the processing cassava. This leads to pollutions of the environs with odour and filthy of the environs with starch solid waste. Literatures show that such pit should be cited away from natural water courses and groundwater abstraction points to avoid possible seepage and contamination [19].

More so, $37.5 \%$ of the respondents used dried cassava peels as source of heat energy in their domestic affairs. This practice is common among poor households during heavy rains when firewood is very difficult to come by [14]. Besides, very few respondents $(10 \%)$ used lagoon as a technology to battle waste management in their processing units. This could be because of technological advancement and it is often used in large cassava processing factory. Stored waste water in lagoons could be treated in aerobic or anaerobic condition before disposal [30]. Cassava waste water stored in lagoon is capable of causing most HCN being evaporated and be rendered innocuous. The problem of the use of lagoon is that it has varying effectiveness, entail a large area of land and are capital intensive in construction [28].

Table 4. Distribution of Respondents According to technologies used by the processors to abate pollution

\begin{tabular}{|l|c|c|}
\hline \multicolumn{1}{|c|}{ Variable } & Frequency & Percentage \\
\hline Open pit & 102 & 85 \\
\hline Dumping in the farm & 80 & 66.7 \\
\hline Source of fuel & 45 & 37.5 \\
\hline Heap waste and burn & 75 & 62.5 \\
\hline Livestock feed & 100 & 83.3 \\
\hline wearing of protective apparatus & 96 & 80 \\
\hline Irrigation & 68 & 56.7 \\
\hline Lagoon & 12 & 10 \\
\hline Land Filling & 78 & 65 \\
\hline
\end{tabular}

*Multiple Responses.

Source; Field Survey, 2018

Table 5 shows that the age of the processors of gari, fufu and tapioca were negative and significant at $5 \%, 5 \%$ and $10 \%$ probability levels respectively. However, for coefficient of age of the starch processors was positive and significant at $1 \%$ alpha level. The negative sign identity of the coefficient of age could be related to decrease in blue-collar strength and conservativeness towards adoption of environmental free technologies associated with advances in age of the processor [1]. Also, the positive sign identity of the age of the processors is stem from information and skills acquired from years of observations and experimentations with various cassava processing technologies aimed at curtailing significantly pollution of the environment [2]. In addition, the coefficient of years of processing experience had direct relation to the dependent variable and significant at $99 \%$ confidence level respectively with gari and fufu processors respectively and $95 \%$ with starch processors. Years of processing experience enhances the cassava processor's ability of maximizing their outputs and profits at minimum cost, with high prudence 
of conserving the ecosystem from possible environs as result of their action [28]. This finding concurred to the finding of [2], who posited that processors year of processing experience correlates with efficiency and effectiveness in accomplishment of processing activities with minimal detriments to the ecology.

As expected, there was positive relationship between educational status of the different processors in the different cassava processing activities as shown in Table 5. Educational attainment of individuals enhances their receptiveness of processing innovation and efficient resource use to avoid pollution of the surroundings [28]. This result was similar to [4] but at variance with the observations by [3] and [27], who opined that educated people often have flair for white collar job compare to agriculture, processing inclusive which they posited that is for poor and illiterate individuals. Besides, the coefficient of credit access was positive and significant at $5 \%$ for gari and starch processors respectively. Credit could be used by these processors in acquiring material inputs, equipment and hiring of labour in adopting environmental free innovations, thus minimizing toxicity of the ecosystem [1]. Finally, the coefficient of extension services had positive effects to all cassava processors forms at different probability levels. A well designed and implemented extension program could not only enlighten the farmers and also generate a better consciousness for the probable benefits of improved agro processing technologies for environmental sustainability [3]. The finding of [1] did not concur to that assertion. They opined that the limitations to extension services such as lack of enthusiasm to attend fortnightly trainings and lopsidedness in home and farm visits could be the probable rationale for the negative association.

Table 5. Results of Logistic Regression Model

\begin{tabular}{|l|c|c|c|c|}
\hline Variable & Gari & Fufu & Tapioca & Starch \\
\hline Gender & $1.854(2.234)^{* *}$ & $0.065(0.765)$ & $1.008(0.006)$ & $2.009(0.009)$ \\
\hline Age of processor & $0.483(-2.209)^{* *}$ & $1.091(-2.098)^{* *}$ & $2.0932(-1.034)^{*}$ & $-3.089(0.084)$ \\
\hline Processing Experience & $2.004(3.089)^{* * *}$ & $0.098(1.620)^{* * *}$ & $2.009(0.119)$ & $0.0094(2.467)^{* *}$ \\
\hline Level of Education & $4.905(3.001)^{* * *}$ & $0.870(4.051)^{* * *}$ & $3.007(4.005)^{* * *}$ & $2.002(3.000)^{* * *}$ \\
\hline Access to Credit & $2.098(2.008)^{* *}$ & $0.654(0.008)$ & $2.0 .980(0.032)$ & $0.003(2.569)^{* *}$ \\
\hline Extension Services & $1.083(2.098)^{* *}$ & $2.007(3.980)^{* * *}$ & $1.098(1.035)^{*}$ & $4.843(3.098)^{* * *}$ \\
\hline
\end{tabular}

Log-likelihood $=\quad-77.3446$ LR chi2 $(12)=117.48^{* * * *}$

Number of cases correctly predicted $=120(87.2 \%)$ McFadden $\mathrm{R} 2=0.3941$

Source; Field Survey; 2018

Table 6 shows that $90 \%, 66 \%, 60 \%$ and $86 \%$ of the gari, fufu, tapioca and flour respondents respectively emphasized on dearth of access to credit. The needs for credit is more among gari and flour processor, which could be attributed to high cost of equipments used in their processing. Nevertheless, credit could aid in procurement of apart from processing equipment, buying of raw materials and in payment of labour [1]. Unfortunately most of the cassava processors are poor resource as they have very poor access to credit. This could be related to their inability to present the required collateral as demanded by lending agencies, high interest rate of the loan and ignorance of loan facility in the banks [29]. As well, the respondents of gari (83\%) and flour (80\%) complained about high cost of processing equipment. This scenario could be related to Naira and Dollar exchange rate as most of the equipment are not fabricated locally but procured from abroad [27]. Furthermore, all the processors $(80 \%, 76.7 \%, 70 \%$ and $73.4 \%$ of gari, fufu, tapioca and flour respectively) reported problem of high costs of labour. The high cost of labour could be attributed to the economic meltdown recently witnessed in the country, hence labourers charge high in order to survive [14]. High cost of firewood was reported by gari $(76.7 \%$ ) and fufu ( $63.4 \%$ ) processors in the study area. The high cost of the resource is more severe in the rainy season and more among processors in urban area [4]. 
As well, the peeling of cassava tuber is usually labour intensive and time consuming tubers as reported by $76.7 \%, 60 \%, 70 \% 76.7 \%$ of gari, fufu, tapioca and flour processors respectively. Therefore, there is need to develop through research cassava tubers that has low peeling density [14]. The very low percentage of peeling under fufu could be related to the fact that most fufu processors don't peel their roots but ferment the unpeeled and remove latter [13]. This process of peel removal is less labour requirement but the resultant product cannot be divorced of odour (). Still, sampled processors especially in more of fufu $(90 \%)$ and less of gari $(83.3 \%)$ complained about long period of fermentation which may not have much to do with the quality of the product, as it is un profitable economic returns. The odour emanating from fermented cassava is very disdainful to the neighbouring people. In addition, some cassava varieties roots cannot readily ferment. Besides, problems of mechanization were reported by fufu and tapioca respondents at $76.7 \%$ respectively. Studies $[10,11]$ show that there is yet to be mechanized fufu processing technologies. Also, $80 \%$ of the fufu and $73.4 \%$ of flour sampled processors complained about poor storage ability of their products, since they could be predispose to high perish ability, especially when stored for reasonable periods of time.

More so, poor infrastructure had been recorded by gari (70\%), fufu $(76.7 \%)$, tapioca $(73.4 \%$ ) and flour (60\%). Poor infrastructure in form of poor road network is capable of increasing cost of transportation of business transaction, reduces payments to processors and increased prices to consumers [31]. Also epileptic or non existence of electricity could result in high cost of production as processors will resort to use of generators to produce heat energy in their business operation, which is very expensive to maintain [3]. The scarcity of water as reported by [11]

is more pronounced in dry season and in places where there is no pipe borne water and no thereby stream or water sources [1]. Moreover, lack of grades and standards was reported by the processors, thus making pricing very difficult. Grading of agricultural produce in the regulated markets and at farm holdings help the processors to get remunerative price for their produce $[2,14]$

Furthermore, irregular supply of cassava tubers was reported in Table 6 by all the different processors. The supply of cassava roots could be affected by the season(roots are easily harvested during rainy season when the soil is more loose than during dry season), road network between the rural and urban, inter rural and farm road to urban and rural areas, the rate of demand of the resource and seasonal harvest [4]. Also, lack of government or institutional support for market affected processors differently (gari (78.7\%), fufu (66.7\%), tapioca (80\%) and flour (46.7\%). This could be inform of poor extension services, inadequate export promotion bodies and among others, thus making the processors being skeptical in undergoing commercial production to avoid risk of business failure [16]. As well, high transaction cost was complained by the respondents (gari (70\%), fufu $(76.7 \%)$, Tapioca $(60 \%)$ flour $(53.4 \%))$. The transaction costs faced by the processors could be as results of corruption by government agents union members who charges or inflates levies and dues payable by processors in the marketing chain[19].

Additionally, poor pricing of cassava products of gari, fufu, Tapioca and flour was complained by $76.7 \%, 70 \%, 66.7 \%$ and $60 \%$ of the respondents respectively. Studies $(31,32 ; 33]$ show that these products have close substitute with semolina and pounded yam, thus could be jettison by consumers at any slightly rise in price. In addition, weak market information was reported by $70 \%$ of gari, $76.7 \%$ of fufu, $60 \%$ of tapioca and $50 \%$ of the processors. Efficient market information especially on up to date is very profitable on prices and other market factors could enable processors to bargain with traders and consumers and to ensure spatial distribution of cassava products from rural areas to towns and between markets[1]. Still, all the respondents (gari $(46 \%$, fufu $(66.7 \%$,$) , tapioca (60 \%)$ and flour $(76.7 \%))$ complained about drying as an impending factor to cassava processing. Processed cassava mash requires about $4-5$ hours of intensive sunshine to dry. Lack of this often results in discolouration and moldings of the mash by bacteria. The use of mechanized dryer could have served better but the price is too exorbitant to the rearch of poor resource processors to afford $[10,11]$. 
Table 6. Constraints to different types of Processors of Cassava Roots

\begin{tabular}{|c|c|c|c|c|}
\hline Variable & Gari & Fufu & Tapioca & Starch \\
\hline & Frequency/Perc & $\begin{array}{c}\text { Frequency/Perce } \\
\text { n. }\end{array}$ & $\underset{\mathrm{r}}{\text { Frequency/Pe }}$ & $\begin{array}{c}\text { Frequency/Per } \\
\mathrm{c}\end{array}$ \\
\hline Poor access to credit & $27(90 \%)$ & $20(66)$. & $18(60)$ & $26(86 \%)$ \\
\hline high price of processing equipment, & $25(83 \%)$ & - & - & $24(80 \%)$ \\
\hline HIgh cost of firewood & $23(76.7 \%)$ & - & $19(63.4 \%)$ & - \\
\hline Poor pricing of products & $23(76.7 \%)$ & $21(70 \%)$ & $20(66.7 \%)$ & $18(60 \%)$ \\
\hline Irregular supply of cassava tubers & $23(76.7 \%)$ & $22(73)$ & $21(70 \%)$ & $22(73.4 \%)$ \\
\hline Poor infrastructure & $21(70 \%)$ & $23(76.7 \%)$ & $22(73.4 \%)$ & $18(60 \%)$ \\
\hline High transaction cost & $21(70 \%)$ & $23(76.7 \%)$ & $18(60 \%)$ & $16(53.4 \%)$ \\
\hline Poor road network & $23(76.7 \%)$ & $21(70 \%)$ & $18(60 \%)$ & $19(63.45 \%)$ \\
\hline Poor market information & $21(70 \%)$ & $23(76.7 \%)$ & $18(60 \%)$ & $15(50 \%)$ \\
\hline $\begin{array}{l}\text { Poor government or institutional } \\
\text { support }\end{array}$ & $23(76.7 \%)$ & $20(66.7 \%)$ & $18(60 \%)$ & $14(46.7 \%)$ \\
\hline Lack of grades and standards, cost, & $23(76.7 \%)$ & $21(70 \%)$ & $19(63.4 \%)$ & $20(66.7 \%)$ \\
\hline High cost of Labour & $24(80 \%)$ & $23(76.7 \%)$ & $21(70 \%)$ & $20(66.7 \%)$ \\
\hline Storageabiility & - & $24(80 \%)$ & - & $22(73.4 \%)$ \\
\hline Problems of Mechanization & $23(76.7 \%)$ & - & - & $23(76.7 \%)$ \\
\hline Peeling & $23(76.7 \%)$ & $14(46.7 \%)$ & $21(70 \%)$ & $23(76.7 \%)$ \\
\hline Fermentation & $27(90 \%)$ & $25(83.3 \%)$ & - & - \\
\hline Drying problem & $14(46.7)$ & $20(66.7 \%)$ & $18(60 \%)$ & $23\left(\&^{\wedge}>\& \%\right)$ \\
\hline
\end{tabular}

Source; Field Survey, 2018

\section{Conclusion and Recommendation}

The results show that most cassava processors were aged, fairly educated, well experienced and members of organization. In addition, the different forms of cassava processing in the study area were into gari, fufu, tapioca, starch and flour.

In addition, the effect of cassava processing on the environment were odour, flies, mosquito dust, dust, cyanide, carbon compound and waste water. Besides, the technologies adopted by the processors in order to abate pollution were use of collection pit, heap and burn, use of protective devices, source of fuel and dumping in the farm. Also, the determinant factors to adoption of the technologies to abate pollution were education of the processors, credit, membership of organization, processing experience and extension services. More so, the constraints to cassava root processing were poor access to credit, high price of processing equipment, Poor pricing of products, poor infrastructure, poor pricing of products, irregular supply of tubers and Poor market information. 
Based on the results the following recommendations were proffered;

(i) There is need to ensure processors' access to educational programs on pollution control through adult program, workshops, seminars and conferences.

(ii) There is need for government to recruit more number of extension agents and as well quip them with knowledge of pollution control.

(iii) Cassava processors should be exposed o credit facilities of commercial banks and microfinance bank at reduced interest rate by government agencies responsible for that. (iv)There is need to encourage old processors to continue in the activities by solving some their constraints to their processing and the new entrants to join also by the government agencies concerned.

(v) Processors should be encouraged to join cooperatives to enhance their access to raw material (cassava roots) at cheap rate, credit at reduced interest rate and access to labour at cheap rate in order to enhance their processing goal without harming the ecology.

(vi) There is need for government to put waiver in imports of agro processing machines in order to curtail maximally high cost of processing equipment, for high efficiency of cassava processing with very minimal harm to the ecosystem.

(vii) Cassava products to be toasted or boiled, must be in well-ventilated apartment to prevent high concentrations of $\mathrm{HCN}$ in the air, thus predisposing the health of workers into serious danger.

(viii) Squeeze water from gari and farinha production must be stored or fermented to reduce the $\mathrm{HCN}$ content through evaporation before release to the surrounding or further utilization.

(ix) If cassava peel is to be fed to livestock, it be first of all be ensiled or fermented to reduce toxic levels of $\mathrm{HCN}$ which is detrimental to the environs.

(x) Agro waste regulatory agency in the country should ensure enforcement of environmental laws for healthy vicinity..

(xi) Cassava processing facilities should be not be located very close important streams, rivers or municipal drinking water sources to avoid possible pollution of the water bodies.

(xii) There is need to enforce all the processing factories either retained within their premises or adequately treat their waste water before discharging it to the environment.

\section{References}

[1] S.I. Ume, et, al;. Technical Efficiency Among Women Cassava Small Holder Farmers In Ivo Local Government Area Of Ebonyi State. 1 - 12, Asian Journal of Agricultural Economics, Extension and Rural Sociology.2016; 17(2)234 - 267

[2] AKO, Nnadozie, et al,.Nigerian cassava potentials in National Economic Development. ScienceJournalofBusinessManagement.Availableat;http//www.sciencepublishinggroup.com/i/ sjb m 2015; 3, 5-1,pp47-49 .

[3] H M Anyaegbunam, . Determination of Labour Requirement for the Production of High Quality Cassava Flour. Proceedings of the $44^{\text {th }}$ Annual Conference of Agricultural Society of Nigeria “LAUTECH 2010”.Pp.15-18.

[4] C I Ezedinma, N Oti, Socioeconomic Issues in the Development of Cassava ProcessingTechnologies in Nigeria. Journal of Sustainable Agriculture and Environment. 2001;3(10):118-125.

[5] FAO, . FAOSTAT. FAO Statistical Data Base Agriculture.2004.

[6] IITA . Integrated Cassava Project: High Quality Cassava Flour Fryer. Printed at IITA.2005

[7] Nweke, T. I. (2004). New Challenges in Cassava Transformation in Nigeria and Ghana. Discussion Paper No.118. Environment and Production Technology Division. International Food Policy Research Institute, Washington. 
[8] J Onwumere. Assets Holding and Determinants of Welfare of Cassava Based Investors in Abia State,Nigeria. Proceeding of 44th Annual Conference of Agricultural Society of Nigeria, 2010; pp.133-136.

[9] T Babaley. Cassava, Africa's Food Security Crop, Consultative Group on International Agricultural Research Volume 3, 2009

[10] J C. Igbeka Agricultural Processing and Storage Engineering, University of Ibadan Press. ISBN: 978-978-8456-07-0, 2013.

[11] L AS Agbetoye, L.A.S. Engineering challenges in developing indigenous machinery for cassava production and processing. In Proceedings of the Annual Conference of the Nigerian Society of Engineers, Ibadan, Nigeria. 2003; 8-12 December pp. 80-86.

[12] O B Oyewole, Fermentation of cassava for lafun and fufu production in Nigeria. Food Laboratory News, 1999; 7, (2), 29-31.

[13] A O Ubalua. Cassava waste: treatment options and value addition alternatives. Afr. J. Biotechnol. 2007; 6(18):2065-2073.

[14] Ehiagbonare J.E., Enabulele S.A., Babatunde B. B., Adjarhore R. (2009). Effect of Cassava Effluent on Okada Denizens. Sci. Res. Essay; 2009; 4(4):310-313.

[15] O K, Achi, et al. Comparative Assessment of Fermentation Techniques in the Processing of Fufu, a Traditional Fermented Cassava Product. Pakistan Journal of Nutrition,2006 5(3) 224229.

[16] K M Oghenejoboh. Effects of cassava wastewater on the quality of receiving water body intended for fish farming, British Journal of Applied Science and Technology 2015; 6(2) 16417

[17] Jefferson, C. "Noise Pollution" U.S. Environmental Protection Agency. Retrieved 2013;0924

[18] S Uzochukwu, et al. Utilization of garri industry effluent. Nigerian J Microbiol; 2006; 15: 8792.

[19] O Osakwe; Effect of cassava processing mill effluents on te physical and chemical soils in Abraka and environs, Delta State, Nigeria. Res. J Chemsci 2006; 2; 7 - 13

[20] O, O Babatunde, O.O. (1999). Design of a model dewatering press for gated cassava mash. J. Agric. Technol, 1999, 7(8). $564-571$

[21] O P Kolawole,et al. Innovative Development of Cassava Processing Machine as Solution to Crisis against Agricultural Systems http..//www.tropentag.de/2012/abstract/full/347.pdf; 2012.

[22] A O Ubalua)Cassava wastes; treatment options and value additions alteratives. African J Biotech2007;6; 2005 - 2075

[23] J O Okafor Impact of effluents from gariprocessing industries on the environment in Bida, Niger State, Nigeria. JEngApplSci 2008. 3;487 - 492.

[24] NPC (National Population Commission), Population census of Federal Republic of Nigeria: Analytical report at the national level. National Population Commission, Abuja.2006.

[25] K.Adebayo. Dynamics of the Technology Adoption Process in Rural-Based Cassava Processing Systems in Southwest Nigeria. International Foundation for Science, Sweden.2006

[26] S O Ojo, A I Ogunyemi. (2014) Analysis of factors influencing the adoption of improved cassava production technology in Ekiti State. , Nigeria, International Journal of Agricultural Science and Natural Resources 1(3), 40-44. 
[27] O P Kolawole. (2014) Cassava Processing and the Environmental Effect. Proceeding of the 4th World Sustainability Forum ; 2014; Pp 1-7.

[28] S. I. Ume, et al;Economics of Gari Processing in Ivo Local Government Area of Ebonyi State,Nigeria.Proceedingsof50 $0^{\text {th }}$ AnnualConferenceofAgriculturalSocietyofNigeria(ASN)“Abi a"

[29] NRCRI U mudike | 3rd - 7th October 2016 | Page 249

[30] K.Tomlins, et al; Improved processing technology for the fermentation of cassava fufu. Presentation at the Eleventh World Congress of Food Science and Technology, Seoul, South Korea. 2001

[31] O B Oyewole, et al; Factors influencing the quality of Nigerian fufu. Poster presented at the Eighth Triennial Symposium of the International Society for Tropical Root Crops-Africa Branch, Benin. 12-16 November 2001. 4p.

[32] S.I. Ume, et al; Role of off-farm income in agricultural production and its environmental affect in South East, Nigeria (A case study of commercial motor cycle business). International Letters of Social and Humanistic Sciences: Vol. 84 (2018) pp 1-13

[33] J J Montilla, Cassava in the nutrition of broilers. In: B. Nestel and M. Graham (Eds.). Cassava as Animal Feed. IDRC, Ottawa, Canada. 2014;pp. 43-50

[34] O O.Tewe, Cassava peel utilization in poultry diets. In: T.R. Terry, M.D. Okoroda and O.B. Arene (Eds.). Root Crops and the African Food Crisis. IDRC, Ottawa, Canada.1987; pp. 150153

[35] C O Ofuya, S.N. Obilor. 1993. The suitability of fermented cassava peel as a poultry feedstuff. Bioresource Technology. 2009; 44: 101-104 